\title{
USER-PRODUCER INTERACTIONS IN EMERGING PHARMACEUTICAL AND FOOD INNOVATIONS
}

\author{
E. H. M. MOORS*, W. P. C. BOON, R. NAHUIS \\ and R. L. J. VANDEBERG \\ Department of Innovation Studies \\ Copernicus Institute for Sustainable Development and Innovation \\ Faculty of Geo-Sciences, Utrecht University \\ Heidelberglaan 2, NL-3584 CS Utrecht, The Netherlands \\ *e.moors@geo.uu.nl
}

\begin{abstract}
In order to study user-producer interaction (UPI) in emerging pharmaceutical and food innovation processes, a classification of user involvement has been developed, including a contextualised view on UPIs. Case studies are performed on two types of UPI: demand articulation in intermediary organisations and interactive learning in consortia, in the pharmaceutical and food sector, respectively.

Regarding demand articulation processes, articulation of problems, needs, demands and expectations through agenda-setting practices is important. Expression and evaluation of demands with other factors leads to moblization of creative potential of prospective users and facilitation of emerging innovation processes.

Regarding interactive learning, geographical, organisational, regulatory and cognitive proximity conditions could facilitate structures for emerging technology development, and codes and networks for frequent interaction between complementary stakeholders. Demands, concerns and opportunities are articulated by shared visions. Organised UPIs via intermediary user organisations or consortia seem to be the important tools for demand articulation and interactive learning involving patient organisations, researchers and private and public organisations.
\end{abstract}

Keywords: User-producer interaction; demand articulation; interactive learning; emerging innovations.

\section{Introduction}

Current pharmaceutical and food innovation trajectories are being confronted with several challenges that revolutionise the way we think about health, and

\footnotetext{
${ }^{*}$ Corresponding author.
} 
predict, prevent and treat illness. These challenges include demographic changes (ageing population), actual health threats (e.g., climate change, metabolic syndrome, infectious diseases) and rapid developments of radically new technologies, such as biotechnology, nanotechnology and genomics (COM, 2007). Additionally, there is an increased demand of better-informed users for higher added value and more personalised, safe and affordable medicines and foods, which largely improve qualityof-life. All these developments lead to more regulatory hurdles, higher liability pressures, reimbursement restrictions and higher development costs (Atun et al., 2007). Furthermore, the pharmaceutical drug development pipelines are nowadays less productive in terms of real innovative therapeutic compounds (FDA, 2005).

Following these problems and trends, successful translation of basic scientific discoveries into novel medicines and new food products results in an increasingly complex and risky business. Innovation studies show that intensified UPI may tackle some of these problems mentioned and this can increase chances for successful innovations. User needs can be identified and their role in the innovation processes strengthened. Producers are interested in societal acceptance of their products, in access to users' knowledge and in mobilising the creative potential of users. Smits and Den Hertog (2007) distinguish five dimensions on which UPI improves the quality of innovation processes: (1) more effective articulation of social needs; (2) enhanced competitive strength of enterprises; (3) improved acceptance and social embedding of knowledge and technologies; (4) improved learning capacity of society as a whole and (5) enhanced democracy.

While user involvement in innovation processes might be beneficial, it remains unclear how to organise UPI in an effective and efficient way. This counts even more when emerging technologies are involved. Uncertainty and flexibility — inherent to emerging technologies — open possibilities for far-reaching user involvement but at the same time ask for thorough organisation of these UPIs in the face of everchanging technology specifications, demands and network structures. Furthermore, users do not constitute a monolithic block. Research in UPI heavily depends on the perception of the different roles of users in innovation processes. From the literature, a whole range of perspectives can be derived. In analysing UPI, it is important to distinguish between different types of user-producer constellations.

To study UPI in innovation processes involving emerging technologies, therefore, first of all, a classification of user involvement needs to be made. Such a classification includes a contextualised view of UPIs, i.e., a view that is susceptible to differences in these interactions in different settings and situations. Developing and using such a model might also contribute to suggestions for improvement of the quality of these innovation systems in terms of articulation of social needs, competitive strength, social embedding, societal learning and democratic quality. 
Therefore, the central research question of this paper is: How to organise and manage UPI in emerging pharmaceutical and food innovation processes?

The focus will be on emerging pharmaceutical and food innovations. In both health care and the food sector, companies increasingly anticipate consumer needs and consumer involvement. In the pharmaceutical industry, user involvement has recently been regarded as a way to make the industry more sustainable, i.e., by assisting in questions about rationing of health care expenditure, level of safety required and the validity of medical needs (Atun et al., 2007; Moors and Schellekens, 2008). The latter, amongst others, refers to users, who are asking for life style medicines, and the pharmaceutical industry that sells more comfort drugs with a controversial medical need or for ordinary, mild, personal, or social ailments (Triggle, 2007) instead of drugs for chronic or life-threatening diseases. Concerning the food sector, new products are not only intended to originally satisfy hunger but also to prevent nutrition-related diseases and to increase the physical and mental well-being of consumers (Menrad, 2003).

The next section provides a theoretical overview of user involvement and UPI, and presents a contextualised classification for studying cases of UPI with regard to emerging innovations. Then, the ways to illustrate and deepen important elements of this model are investigated and the applied research methodology is described. Case studies about demand articulation and interactive learning in the pharmaceutical and food sector respectively, provide a dataset for analysis. Next, the results of the case studies are presented and discussed. The paper ends with conclusions and recommendations.

\section{Theory and Classification of UPIs}

In general, pharmaceutical and food innovation processes represent science-based innovation trajectories, carried out by a network of interrelated actors, such as universities, research institutes, producers, government and consumers. They are guided by expectations about potential customers and new product innovation, adoption and diffusion. As the majority of new products fail, new product development, especially in emerging technological fields, is a risky endeavour, but essential for the health and survival of a company (Cooper, 1993). The success of new products is improved when there is true added value to the consumer (Griffin, 1996). It is difficult, however, to fully understand user needs and preferences, and to balance them with the strategy of producers to make a product that satisfies users better than competing alternatives. After all, users are not always able to articulate their needs, preferences or wishes, due to the fact that they are not fully aware of all (latent or future) possibilities of a new technology or do not want to share their creative ideas 
and opinions (Hamel and Prahalad, 1994; Griffin, 1996). Furthermore, identifying opportunities for new products, especially for radical new, emerging products, is quite difficult, as these products "can offer new, unique, or superior solutions to users' needs and can create entirely new markets" (Schmidt and Calantone, 2002). Accordingly, incorporating the "voice of the consumer" in early stages of new product development has been recognised in various studies as a critical success factor (e.g., Griffin and Hauser, 1993; Van Kleef et al., 2005) but at the same time, this voice is difficult to assess.

The traditional economics literature has mostly ignored the dynamic relation between research and product development choices of firms on the one hand and user needs and preferences on the other. In innovation studies, the dynamics of this relation is increasingly perceived as a co-evolutionary process, an institutional interplay in which many heterogeneous stakeholders interact in complex ways. The emergence of new functionalities of a product innovation is a particular aspect of the widening process of co-evolution of a new technology and its users. More or less heterogeneous user groups provide feedback about how new technologies, with varying degrees of flexibility regarding product specific characteristics and uncertainty about potential applications and related ethical, legal and social aspects, match their needs, preferences and performance criteria. These aspects become articulated in demands and interactions between users and producers. Accordingly, users are increasingly recognised as important co-developers of innovations, often developing new functions for technologies, solving unforeseen problems and demanding innovative solutions. This even holds true for science-based innovation processes such as in the pharmaceutical and food sectors (e.g., Lütje, 2003; Verbeke, 2005; Lettl et al., 2006; Urala and Lähteenmäki, 2007).

This paper attempts to bridge the gap between the rather classic linear innovation model for understanding pharmaceutical and food innovation processes, and more recent theorising on innovation systems, characterised by feedback and co-evolution, in which UPI plays an important role. Demands, needs, wishes and concerns of users not only become visible in the end stage but often are articulated throughout the innovation process, for example, in research agendas of firms, wishes of retailers and experiential knowledge of users. Via such interaction and articulation processes, important societal aspects are introduced in innovation processes (Nelson and Winter, 1982; Rip and Kemp, 1998). However, effective involvement of users and other stakeholders by no means is easy and can be improved considerably. The organisation of an effective UPI puts new requirements on the innovation systems in which these firms have to operate. Changes in science and technology as well as the context in which pharmaceutical and food firms have to manage their innovation processes will lead firms to replace their linear innovation model by a systemic, multi-actor model. Taking a holistic perspective of innovation 
(Atun and Sheridan, 2007), and involving users in innovation processes is an important consequence hereof (Smits and Boon, 2008).

A broad set of disciplines has focussed on the role of users in technology development, ranging from cultural and feminist literature to science, technology and innovation (STI) studies. The latter has recently shown that intensified, and welldesigned UPI may increase chances for successful innovations (e.g., Von Hippel, 1988; Lundvall, 1992; Coombs, 2001; Geels, 2002; Smits, 2002; Moors et al., 2003; Oudshoorn and Pinch, 2003; Rohracher, 2005; Smits and Den Hertog, 2007; Boon et al., 2008; Nahuis et al., 2008; Smits and Boon, 2008). Apart from consensus about the (potential) positive impact of users on innovation processes, however, there is not much agreement on questions like how to perceive and manage UPIs in different contexts and/or with different goals.

To develop a more specific and contextualised view on UPI, we have performed a literature review about how different forms of interaction might contribute to the processes of co-evolution in different circumstances (Nahuis et al., 2008). The outcome of the review is an overview of types of interaction. These "types" are inspired by theoretical concepts, such as demand articulation, learning by using, learning by interaction, innofusion, frame sharing and domestication (Teubal, 1979; Rosenberg, 1982; Fleck, 1988; Silverstone and Hirsch, 1992; Bijker, 1995; Boon et al., 2008). They are classified according to a scheme with three axes:

- the phase of technology development

- the level of technological flexibility

- the heterogeneity of the user population

It is widely acknowledged that the characteristics of technology development change along different phases of technology development (Collingridge, 1980; Utterback, 1994) with important consequences for the types of UPI that should be employed in these different phases (Rip and Schot, 2002; Stewart and Williams, 2005). Somewhat simplified, we distinguish between an early phase when actors are building up a protected space, and a later phase in which the technology enters the wider world. Yet, the phase of technology development is the least relevant axe in the current paper, because we focus on emerging technologies, which, by definition, are in an early phase of development.

Regarding the flexibility of the technology, we use Fleck's (1994) notion of configurational technology. Configurational technologies are built up from a range of components to meet the specific requirements of particular user organisations. A technology is called flexible when different configurations with different performance characteristics are reasonably possible. If not, we speak of specific technology. 
Turning to the heterogeneity of the user population, we note that there are several sources of heterogeneity: different users have different capabilities and knowledge bases (Akrich, 1995), user contexts are often unique as a consequence of contingent historical developments (Fleck, 1994; Garrety and Badham, 2004), and there may be different kinds of users of the same technology that have different needs and concerns (e.g., medical professionals, nurses, patients and hospital administrators in case of medical technologies) (Oudshoorn and Pinch, 2003). Although "users" is understood as an emerging category that is amenable to change (Martin, 2001), there are nonetheless important differences across and within technology fields as to its degree of heterogeneity. For example, users of apartments appear to be much more homogeneous than users of addiction treatments (Franke and Von Hippel, 2003). We speak of homogeneous user populations when many users are satisfied with the same standard product. Users are heterogeneous when user contexts are very unique or complicated, or when users have conflicting interests in the development of certain technologies.

These three dimensions constitute a classification scheme for UPI. Theoretical concepts for UPI are derived from a number of relevant bodies of literature, namely evolutionary economics, constructive technology assessment, social construction of technology, semiotic studies and cultural studies. ${ }^{1}$ The literature review shows how the requirements to UPI vary with the phase of development, the flexibility of technology and the heterogeneity of users. Table 1 presents the results of this review.

This classification scheme becomes especially useful when it is not only clear which types of UPI are relevant in what circumstances, but also what the main conditions and operations of these types are. We consider this scheme as an agenda for future research into the whole spectrum of UPI and we invite other scholars to join this endeavour. As a start, this paper somewhat arbitrarily zooms into the two emphasised types of UPI and explores the purposes, conditions, mechanisms and outcomes of demand articulation in circumstances of specific technology and homogeneous users, and interactive learning in circumstances of specific technology and heterogeneous users.

\footnotetext{
${ }^{1}$ Clearly, this review could be extended with concepts from other bodies of literature, such as democratisation theory, marketing research and risk research. For an overview of the literature about science, technology and democracy, see Nahuis and Van Lente (2008) and Bucchi and Neresini (2008). For a discussion about incorporating consumer preference in product development in the marketing literature, see Schmidt and Calantone (2002), Griffin and Hauser (1993) and Van Kleef et al. (2005). For a comprehensive discussion about the difficult relation between value pluralism and risk assessment methodology and its implications for public participation, see Renn (1998), Stirling (1998) and Fischhoff (1995).
} 


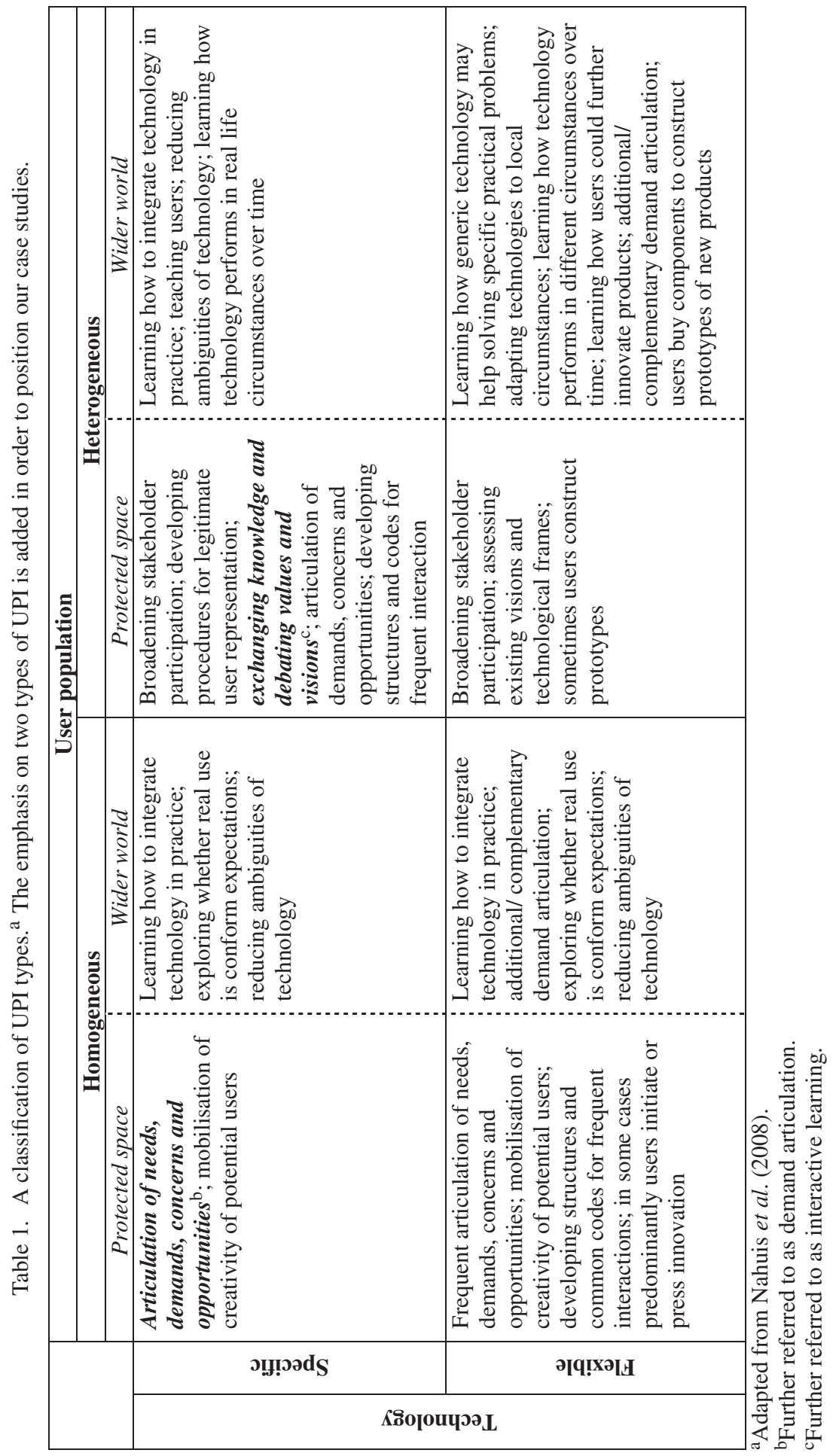


In both demand articulation and interactive learning, a distinction can be made between first-order and second-order learning (e.g., Sabatier, 1987; Cohen and Levinthal, 1990; Boon et al., 2008). If the technology is adapted to fit the user environment, first-order learning takes place. It refers to instrumental knowledge concerning specific knowledge for solving a problem within an existing framework. The aim is to make existing user preferences explicit, which can then be translated into design requirements. Second-order learning is conceptual knowledge related to the framework itself and the shared vision amongst users in this framework. In second-order learning users experiment with new ways of using artefacts, allowing them to question established assumptions about functionalities of technologies (underlying assumptions), cultural meanings, user practices and preferences.

\section{Research Methodology}

According to Table 1, demand articulation is important in several circumstances. Demand articulation is defined by Boon et al. (2008) as "an iterative, inherently creative process in which users try to unravel preferences for and to address what they perceive as important characteristics of an innovation". Demand articulation takes place when preferences of users are made explicit, in such a way that it prompts other actors to (re)act. In many cases, users do not yet have precise demand requirements and a clear view of relevant product attributes. Users' needs and possible alignments with technological opportunities cannot be discovered ex-ante, as scholars like Teubal (1979) and Clark (1985) stressed. They have to be constructed and negotiated in a process of mutual articulation and alignment of demand and supply. In this process, the role of intermediary organisations, such as mediators, advocacy groups or spokespersons, is relevant.

Although demand articulation is important in several circumstances, we selected a case with relatively homogeneous users and a rather specific technology in accordance with our interest in emerging pharmaceutical technologies. In a pharmaceutical discourse, demand is fundamentally linked to disease. Defined by a common disease, patients constitute a relatively homogeneous population. Disease does, however, not fully determine demand; there are several related aspects of demand that remain to be articulated in relation to the characteristics of an innovation, such as the safety and efficacy of drugs. Pharmaceuticals are generally specific, because they are R\&D intensive and composed of components that cannot be configured differently without losing essential performance characteristics.

The second type of UPI under study here is interactive learning. Users and producers are experimenting with the new technology and interactively learn on 
a variety of dimensions. Then alignment takes place (Rosenberg, 1982; Lundvall, 1988). Interactive learning is important when information and knowledge are tacit and difficult to communicate. This is generally the case in early phases of technology development (Vandeberg and Moors, 2007). Moreover, learning by interaction is crucial in any case where frequent interaction is required, i.e., when actors have to rely on one another's expertise. Such reliance exists among others in the combination of specific technology and heterogeneous users, because such technologies are bound to fail without compromise or alignment of the needs and concerns of heterogeneous users (Nahuis et al., 2008).

We selected a case from the field of nutrigenomics as an example. Users are heterogeneous in this case, since they come from science, industry, government and the public, bring in their own expertise and express their own needs and concerns. The technology can be characterised as specific, given the knowledge intensive outcomes of interactive learning. The sort of technology-as-knowledge, which interactive learning currently helps developing in nutrigenomics (about gene-nutrient interactions) is not flexible in the sense that it can be rather freely recombined to get different results; recent insights at best reveal specific gene-nutrient relations.

We should also note that both the pharmaceutical and the food innovation system face new challenges in the era of genomics with implications for the classification presented here. The emergence of genomics is said to initiate three trends: (i) from cure to prevention (more emphasis on diagnosis), (ii) from relatively homogeneous user populations (patient groups) to personal needs (a unique set of predispositions) and (iii) from specific products to customisable therapies/diets. Nutrigenomics researchers, for example, state that the purposes at the horizon of the research landscape are to capture human genetic diversity with nutrigenomics and serve individual needs with tailored diets and therapies (Kaput et al., 2005). Similar expectations are expressed for pharmacogenomics, although patient stratification in substantial groups will probably still be preferred to pure individualisation of demand (Royal Society, 2005; Trusheim et al., 2007). Nevertheless, future cases should perhaps be positioned differently in the classification scheme (Table 1) as these trends are arguably directed towards the lower-right corner of the scheme. While such visions still mainly figure at the level of promises and expectations, the case studies presented here could function as "baseline studies" to be confronted with such trends in order to explore the implied shifts in innovation systems. Such an exploration yields important insights for innovation management and policy in general and the future organisation of UPI in particular.

The case studies in this paper are presented to illustrate and deepen the classification of UPI types; they analyse the conditions and mechanisms for demand articulation in current pharmaceutical and interactive learning in current food innovation systems (Boon, 2007a,b; Vandeberg and Moors, 2007; Boon et al., 2008; Nahuis 
et al., 2008; Vandeberg, 2008a,b). These studies focus on intermediary organisations and consortia, respectively. The reason for this focus is that these are the settings where such articulation and interactive learning processes typically occur (Kaput et al., 2005; Boon, 2007a,b; Vandeberg, 2008a,b). Therefore, this paper not only explores the purposes, conditions, mechanisms and results of interactions in these different settings, but also allows for a comparison of the relative merits of these different ways of organising UPI.

However, there are some limitations to this comparison, which follow from methodological considerations in the case studies. For investigating demand articulation, first, an agency perspective is adopted. The main reason is that intermediary organisations are important agents in the process of demand articulation and following their activities is a proper heuristic for identifying needs and concerns and for examining the role of articulation in innovation processes. Interactive learning in consortia, in contrast, is studied from a structure perspective, because consortia are brought into being due to the fact that they are believed to form an adequate structure for learning. A related conceptual difference is the inclusion of time as a variable. Whereas demand articulation from an agency perspective necessitates following an actor over time, understanding interactive learning from a structure perspective predominantly requires mapping spatial, cognitive and cultural aspects of interaction. ${ }^{2}$ In other words, demand articulation is studied following a processbased model, whereas interactive learning makes use of a variance model (Poole et al., 2000).

Studying demand articulation implies the importance of following stakeholders in long-term debates, the activities or "events" they participate in, and the related demand statements they make in the context of these events over time. To analyse the time-ordering and the changes in content-related issues such as demands in a structured way, the "event history analysis" method was used as devised by Poole et al. (2000). Examples of such events include conferences, published reports, meetings and deliberations. We explicitly followed one patient advocacy group, studying how they formed and expressed their demands and what the content of these demands was.

The data were obtained from the archives of the patient advocacy group, including minutes of meetings (board meetings but also those of committees), letters, reports and evaluation. Other data sources include more open-access ones. In addition, we conducted interviews with several representatives of the patient group, and substantiated these with interviews with representatives from organisations that

\footnotetext{
${ }^{2}$ See Boon et al. (2007a,b, 2008, In Press), Vandeberg \& Moors (2007), and Vandeberg (2008a,b) for further clarification and argumentation of research design decisions.
} 
frequently interacted with the patient organisation. These interviews were primarily meant to clarify archival information, provide the easiest inroads to the data, and by asking "why-questions" uncovering the underlying assumptions behind the demands that were found.

For the study of interactive learning in emerging technologies, a framework was developed that incorporates structural aspects, like proximity/distance between stakeholders on several dimensions, as well as process variables like knowledge flows, network formation and the role of a prime mover and intermediaries therein. Indicators for these variables are identified in order to distil and analyse relevant data.

General information on (the emergence of) consortia, the stakeholders within consortia and policy surrounding these consortia was derived from consortia and stakeholders' websites and complemented with internal and policy documents (publicly available). Scientific articles and patents were used to assess the outcome of the consortia and news articles and other (e.g., websites) publications reporting about the consortia were used as complementary material. The interactive learning process was assessed through interviews with consortia stakeholders. The most knowledgeable respondents were selected, based on their participation in projects and overall understanding of the consortium. Some concepts could also be assessed quantitatively. UCINET $6^{3}$ was used for co- and cross-citation analyses, i.e., cognitive proximity, and Google Maps ${ }^{4}$ to analyse the travelling time, i.e., geographical proximity, between the stakeholders in a consortium.

\section{Results}

This section presents the results on demand articulation mechanisms in emerging pharmaceutical innovations and interactive learning conditions in emerging food innovations, respectively in order to illustrate the developed classification of UPI types, i.e., phase of technology development, flexibility of technology and heterogeneity of users. The first part focuses on demand articulation processes of the Dutch Neuromuscular Diseases Organisation VSN (Vereniging Spierziekten Nederland), a patient group that works, amongst others, on emerging drugs for Pompe disease. The second part illustrates interactive learning conditions in the case of emerging nutrigenomics developments in the Dutch Nutrigenomics Consortium.

\footnotetext{
${ }^{3}$ http://www.analytictech.com/downloaduc6.htm.

${ }^{4} \mathrm{http}: / /$ maps.google.com/
} 


\section{Demand articulation of a patient organisation in the context of Pompe drug development}

The VSN is a patient organisation that was founded in 1967 by a group of parents with children who had a neuromuscular disease. The organisation shared information with other patient organisations for the need to support information provision to patient members, and set-up mutual help services. The VSN dealt with several promising, emerging technologies, such as gene and stem cell therapy, in their role of information translator. Nevertheless, what makes the VSN quite unique in the Dutch health care context, is their contribution to research and development of diagnostics and therapy for neuromuscular diseases.

Developments in pharmaceutical science and technology spurred the patient organisation to pursue other directions of action. Already in the 1970s, the VSN recognised that many neuromuscular diseases are genetically determined. The VSN's focus on research pushed to follow the train of scientific events: the location of the disease susceptibility gene should lead to the identification of this gene. In turn, this discovery contributed to finding a diagnostic tool and producing more information about the natural course of the disease. Subsequently, the products of the gene (proteins) were identified, which might be the starting-point for therapy. In order to control part of these developments, the VSN played a part in raising funds, and supporting scientific work through funding international research networks. The first disease area in which this "train of scientific events" model was used was Duchenne muscular dystrophy. But Pompe disease was the most prominent case in which the VSN became involved and articulated demands. This case led to the development of a therapy in which a deficient enzyme in Pompe patients was replaced, i.e., enzyme replacement therapy.

Pompe disease (glycogen storage disease, acid maltase deficiency) is a rare, genetic, metabolic disorder causing progressive skeletal muscle weakness. After the discovery and cloning of the gene that is responsible for deficiency in the production of the enzyme acid alpha-glucosidase that causes Pompe disease, at an Erasmus MC research group in 1990, this group looked for possibilities to upscale the production of enzymes using this genetic knowledge. It chose to ally with the Dutch biotechnology company Pharming that worked with transgenic animals and had produced a transgenic bull. Genetic modification of animals for producing enzymes had become contested in the political debate at that time. Several actors, including the legislator, called for stricter regulation. The VSN tried to voice the anxieties of patients and the biomedical world, but their demands remained rather marginalised. Later, the VSN condemned promotional actions by an animal rights group and had considerable more success. 
The VSN also tried to influence other aspects of the drug R\&D process, such as the set-up of phase I/II clinical trials, demands about compassionate use of the Pompe drug during phase III-clinical trials (i.e., the use of the drug before regulatory approval by very ill patients who have no treatment alternatives), the approach and estrangement later on of the two companies involved (Pharming and Genzyme), the reimbursement of orphan drugs, the drug's approval for late-onset Pompe patients, and putting newborn screening for Pompe on the agenda. Part of these advocacy efforts was actively channelled through an international spin-off, the International Pompe Association (IPA), founded in 1999.

When following the events in which the VSN was engaged in over time, the articulation of demands could be analysed. The demands of the VSN became increasingly concrete. For example, regarding the aforementioned animal rights groups the VSN converged its opinions and sharpened its argumentation. Although the VSN was following the events that were topical at various moments of the event cycle, the organisation mostly took a proactive stance towards Pompe drug R\&D. The influence on the drug $R \& D$ process was substantial, but only in terms of easing the communication between actors and by creating the right conditions, e.g., stimulating clinical trials and reimbursement. Although the VSN - and IPA - had influence on the speed of the innovation process, addressing contested issues and filling-out of the innovation process and the implementation of the drug, they did not have an impact on which technological alternative should be chosen to enter the market as a drug. For this, the interests and the power of the companies involved, Pharming but later also Genzyme, were just too great.

The VSN was thus engaged in first-order learning, i.e., converging demands, problems and ideas. The demands focussed on drugs based on the enzyme replacement therapy principle, the speedy development of this drug, and related boundary conditions, such as reimbursement. The VSN and the patients it represented were neither in the position to be particular nor powerful enough to impose other treatment alternatives. Moreover, the VSN also learnt on a second-order level by developing their underlying assumptions. The assumptions include positioning themselves towards other actors, e.g., by stressing the importance of the "natural alliance" between Erasmus MC and the VSN; constructing the role it played of, amongst others, proactive broker and representation of patient interests, as a model for other neuromuscular disease associations to follow; regarding the timing of advocacy activities; and trust that the VSN puts in other parties. The latter refers to the fact that the VSN does not trust other parties on face value anymore (some interactions caused the VSN to re-define its faith in others), but always requires some base of evidence (Boon, In Press, 2008). Finally, these first- and second-order learning processes also influenced each other (see Fig. 1) by legitimising demand articulations 


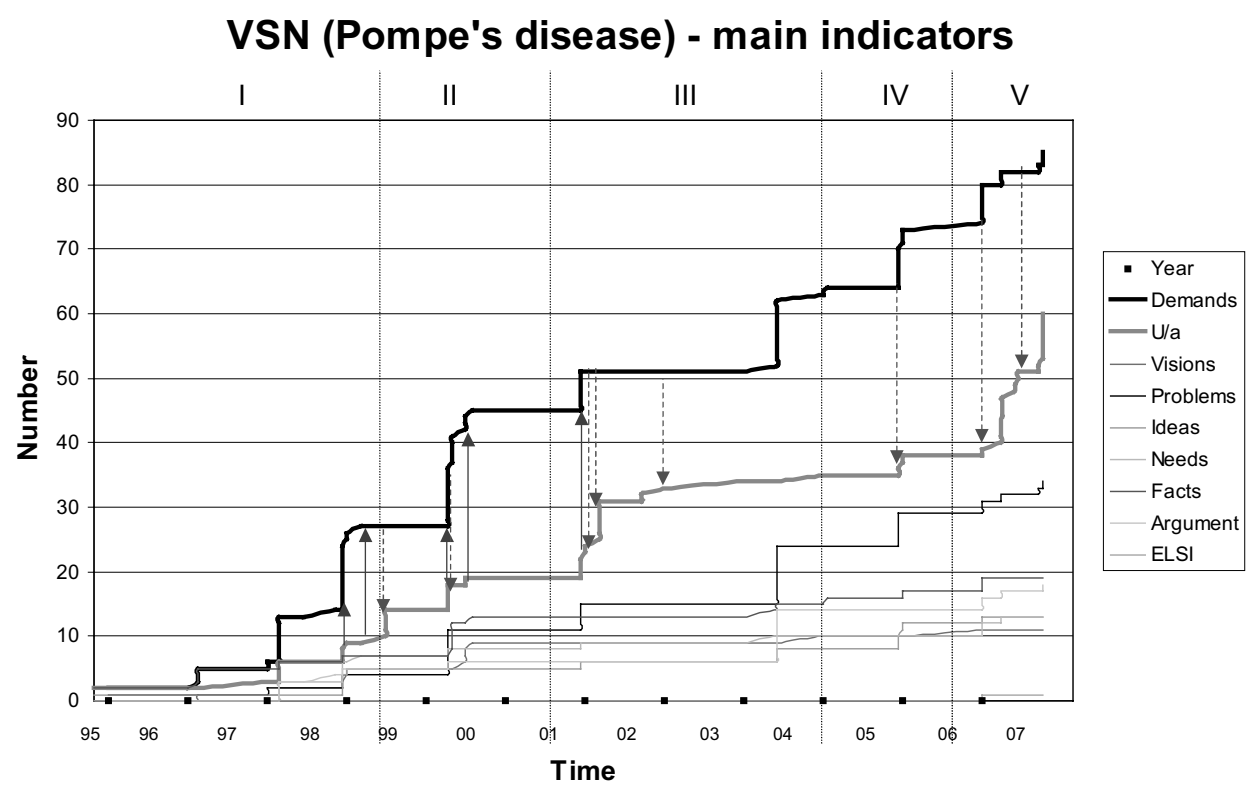

Fig. 1. Cumulative amount of events and statements in the event cycle on ERT for Pompe disease. The main categories are demands (subdivided into demand categories, such as visions, problems and needs) and underlying assumptions ( $\mathrm{u} / \mathrm{a})$, which are interlinked through arrows.

using underlying assumptions (upward arrows), and evaluating underlying assumptions following demand articulation (downward arrows).

To conclude, this case showed that the VSN was much engaged in representing their patient members towards other actors by (1) putting the demands from these members on their agenda, (2) synthesise these demands using its own underlying assumptions, and subsequently (3) express and (4) evaluate their demands to other actors. These other actors, including companies, research groups and government agencies, were influenced by these advocacy efforts and resulting demands. This user involvement led at least to facilitating the Pompe drug innovation process, in which the VSN constructed and articulated their demands, and made these demands more concrete in the process. Concrete problems, ideas and needs overshadowed future visions and expectations (Fig. 1). Moreover, the VSN took on issues in a proactive way, thus, breaking out of the protected space that was proposed in the theoretical part, by also taking into account conditions that would become significant further along in the innovation processes. Examples include reimbursement and newborn screening. This involved second-order learning as well, most prominently getting to know the organisation of drug innovation processes. 


\section{Interactive learning of a consortium in the context of nutrigenomics developments}

In the emerging field of nutrigenomics developments, interactive learning between heterogeneous users is localised in the relative protected space of consortia (Kaput et al., 2005; Vandeberg, 2008a). These co-operating users of each other's knowledge are both firms and research institutes in the food innovation system. The Dutch Nutrigenomics Consortium (DNC) is such a consortium of nutrition research organisations and food companies co-operating in the Wageningen Centre for Food Sciences (WCFS) and medical/genetics research organisations co-operating in the Centre for Medical Systems Biology (CMSB) that joined their forces to form a nutrigenomics research collaboration.

The DNC was operational for the period 2003-2007. The outcome of the interactive learning process regarding emerging nutrigenomics developments is represented in scientific knowledge (i.e., first-order) and shared visions (i.e., secondorder) in the DNC consortium. The shared vision in the DNC is the result of an "attuning process" between the top-down mission at the Dutch governmental level, which co-financed the DNC, and the bottom-up emergence of a shared vision within the DNC (Fig. 2). Although the shared vision slightly emphasised the unfolding of metabolic stress as a topic and conservatively predicted future applications of food components, during the scientific nutrigenomics research itself a shift within the shared vision became visible. Through the scientific research, the knowledge flows within the DNC and the resulting outcome (e.g., scientific articles), it was found that nutrigenomics is far more complex than thought during the formation of the DNC. Therefore, the shared vision and the entailed expectations shifted from solving the metabolic stress/ syndrome, with concrete food products available in a wider world, to understand the basic scientific principles responsible for or leading to the metabolic syndrome.

The (shifting) shared vision and the scientific knowledge outcome of the DNC are the result of interactive learning, which encompasses characteristics and conditions of the interactive learning process. Network formation, the role of prime movers and intermediaries, and the flow of knowledge are important interactive learning characteristics when emerging technologies, such as nutrigenomics are concerned. These interactive learning characteristics are influenced by various proximity conditions, including geographical, cognitive, regulatory, cultural and organisational proximity (cf. Vandeberg and Moors, 2007). In the case of the DNC consortium, several conditions influencing the interactive learning process are visible.

It is assumed that firms located in areas with other firms have better innovation performance than more isolated or distant firms: organisations benefit from being located close to other organisations (Weterings, 2006). In science-based 


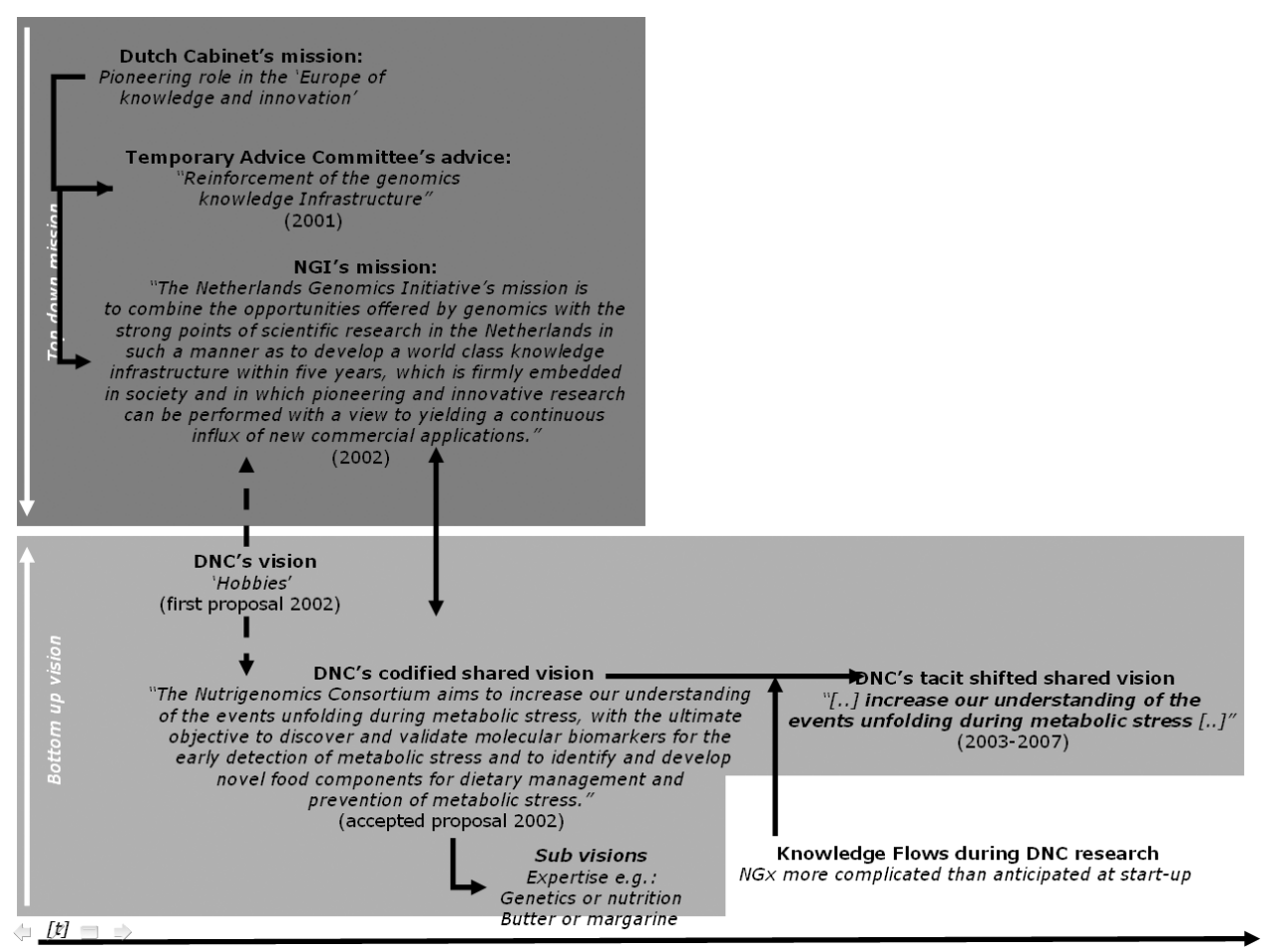

Fig. 2. Construction of a shared vision (second-order learning) and influence of scientific knowledge (first-order learning).

emerging technologies complex knowledge is exchanged between knowledge users. Often, this knowledge is tacit (Malmberg and Maskell, 1999; Doloreux, 2004) or it is so complex that it needs a tacit explanation (Howells, 2002). The exchange of tacit knowledge between users is enabled through face-to-face interaction (Feldman, 1994; Gertler, 2003). Geographical proximity facilitates face-to-face meetings, and as such geographical proximity is an important condition for tacit knowledge exchange and interactive learning (Feldman, 1994; Gertler, 2003). During the construction of the DNC and especially within the research projects, the close geographical co-location of the stakeholders within the Netherlands enabled the exchange of both tacit and complex knowledge (e.g., regarding scientific nutrigenomics knowledge) between knowledge users in the DNC. As such, geographical proximity enabled the knowledge flows within the DNC which lead to interactive learning between the users.

The potential for interactive learning between users is also influenced by the cognitive distance between the stakeholders and their absorptive capacity. In order to incorporate external knowledge flows into one's own knowledge system, the 
cognitive distance should not be too big (Boschma and Lambooy, 1999). In other words, a certain amount of absorptive capacity is needed. Cognitive distance is manifested in the different technological foci of DNC stakeholders: In medical research at the CMSB, well-defined pathways and interactions with pharmaceutical drugs of known composition are studied, whereas in nutritional studies of the WCFS the focus is on the pluriform, direct and indirect effects of food on homeostasis (Kaput et al., 2007). Therefore, there is some cognitive distance between the stakeholders with a nutritional or medical background in the consortium. The distance itself created the potential for the users to learn, if they would be able to cross this distance. According to the interviewees, the DNC researchers have been able to learn from each other and use each other's knowledge. The combination of the cognitive distance between and absorptive capacity of the users was a pre-requisite for interactive learning, facilitating knowledge flows that resulted in scientific articles and a (shifted) shared vision. In those instances in which the users were unable to cross the knowledge gap among them, intermediaries functioned as translators or knowledge brokers (Geurts, 1993) between complementary users that are at the outer ends of the nutrition-genomics spectrum. Within the DNC, scientific knowledge was translated through boundary objects (Star, 1989): mouse and human genetics models were used which were both familiar to nutritional scientists (at WCFS) and medical/genetics experts (at CMSB). As such, these boundary objects could be regarded as intermediaries. This enabled the users to discuss and exchange knowledge from a mutual starting point. At the same time, translations from basic science to possible applications were organised in exemplification projects. These made it possible to apply knowledge more often for different purposes and to explore future applications in the wider world of nutrigenomics products.

Regulatory proximity at the innovation system level reduces uncertainty about return on investment (Autio et al., 2008) and stimulates research organisations, which probably would otherwise not endeavour on this research, to co-operate in risk bearing, costly long-term projects and to form networks. The users in the DNC in the Netherlands are all subject to the same regulations at the food innovation system which are directly related to the EU directives, i.e., the EU Novel Food regulation and proposal for a regulation of the European Parliament and of the council on nutrition and health claims made on foods (COM2003/424). These regulations encompass the foresight that nutrigenomics products will be allowed onto a protected market space in the EU. As such, these regulations granted some future return on investment and stimulated the DNC stakeholders to form a network and to perform co-operatively costly, risky science-based nutrigenomics research.

Uncertainty about co-authorship and IPR might hinder the free flow of knowledge within a research consortium that is dependent on this knowledge interchange. Regulatory proximity at the network level, in the form of contracts and mutual 
non-disclosure agreements (NDA) of knowledge outside the consortium and IPR, reduce the risk of unwanted spill-overs. As such, these agreements encourage knowledge flows. Therefore, the organisations within the consortium found it important to make clear arrangements regarding IPR (even though IPR arrangements might not be economically beneficial (Dosi et al., 2006)). Before the WCFS and CMSB joined their forces for nutrigenomics research, they had their individual patenting mechanisms. Discussion during the formation of the DNC resulted in a mutual agreement that satisfied the CMSB and the WCFS. IPR arrangements prevented unwanted spill-overs because it was clear who owns which knowledge and under which conditions others could use this knowledge (e.g., through patents). Unwanted spill-overs were prevented further by the agreement not to conduct similar research simultaneously outside the DNC. So, the users knew that their knowledge would stay within the consortium and it was clear under which conditions who would be involved in publications and possible patents. Therefore, the users, were tended to let their knowledge flow more freely. At the same time, the users have to trust each other that they will not misuse complementary knowledge for their sole benefit. This is especially important because of the ubiquitous character of tacit knowledge. Tacit knowledge flows more easily in the presence of shared trust (Malmberg and Maskell, 1999). The main difference between the different organisations (i.e., universities, research institutes and companies) within the DNC consortium is their different focus on outcome, resulting from the different underlying incentive structures. The differences between the foci of universities and companies on publications and patents respectively, might lead to a conflict: if a finding has been published (in a scientific journal) it can no longer be patented because it is impossible to trace the originality of the idea by the patent applicant.

Cultural proximity is related to these different underlying incentive structures for science and industry, which might induce reluctance to knowledge sharing and could block knowledge flows and interactive learning (Dasgupta and David, 1994; Frenken and Van Oort, 2004). Although the stakeholders within the DNC already agreed on NDA and IPR in the mutual agreement, a culture of shared trust was very important. For the collaboration in the DNC, this trust was partly based on earlier experiences of the stakeholders with each other. At the same time, due to the emerging, pre-competitive phase of nutrigenomics research, no rivalry existed between the knowledge users in the DNC that could lead to an offensive situation, which would also be prevented by the IPR and NDA agreements in the mutual agreement.

Finally, the "production" and co-ordination of complex knowledge is determined by the organisational proximity. Organisational proximity encompasses the flexibility that enables individual pursuit of knowledge goals, and co-ordination that enables the combination of complementary knowledge flows (Boschma, 2005). The DNC 
was set up as a virtual network in which nutrigenomics research was organised around topics and "closely interacting work packages [...] headed by WP leaders, who are responsible for scientific leadership and project management of their WP" (DNC). Within the work packages (WPs), several organisations could participate. Each WP was managed individually by a WP leader, which resulted in flexibility at the WP level. From the beginning, these activities were co-ordinated through the DNC as arranged during network formation. This also entailed standardisation that would make data exchange and knowledge flow between WPs easier.

To conclude, interactive learning processes did take place in the DNC consortium with increased scientific knowledge and a shared vision as concrete outcome. The shared vision shifted: increased understanding of the underlying mechanisms of the metabolic syndrome called for studying these mechanisms further before turning to developing concrete products for the wider world. By studying the influence of proximities on network formation, prime movers, intermediaries and knowledge flows, the interactive learning processes of specific emerging nutrigenomics developments regarding metabolic stress in the protected space of the DNC consortium have been unravelled. The results show that EU regulations reduced the future return on investment, which encouraged the knowledge users in the consortium to form a network and embark on nutrigenomics research. Within this network, the mutual IPR and NDA arrangements prevented unwanted spill-overs, which facilitated the free flow of knowledge. Knowledge flows were further stimulated by a culture of shared trust. The cognitive distance between the heterogeneous knowledge users in the consortium was dealt with by boundary objects, which enabled them to bridge knowledge lacunas based on mutual starting points. The geographical collocation enabled face-to-face interactions between the users, in which tacit and complex knowledge was exchanged. The set up of WPs granted both flexibility and co-ordination of the complementary knowledge in the DNC.

\section{Concluding Remarks and Discussion}

The aim of this paper is to understand how to organise and manage UPI in emerging pharmaceutical and food innovation processes. These insights could lead to recommendations for improving the quality of these processes in terms of articulation of social needs, competitive strength, social embedding, societal learning and democratic quality. The paper focuses on developing a classification scheme for UPI, in which various theoretical concepts for types of UPI are depicted. It is argued that the requirements for UPI vary with the phase of technology development (in protected space or in wider world), the flexibility of technology (specific vs. flexible) and the heterogeneity of user populations (homogeneous vs. heterogeneous). This classification scheme offers a potential base for evaluating and improving the organisation 
and management of UPI in innovation processes, because it draws attention to the relation between relevant types of UPI in a certain case and the wider context of the case. After delineating their case, innovation managers are encouraged to consider a particular set of interaction possibilities. To fully realise the management potentials, however, two points need to be taken into account: (1) investigating how particular cases indeed fit into the categories of the scheme and (2) investigating how, once a particular type of interaction is considered worth pursuing, the interaction should actually be organised. Both these points are addressed in this paper, albeit partially, and are discussed below.

First, in order to investigate whether the classification scheme is robust and in which circumstances, this paper zoomed into two types of UPI, i.e., processes of demand articulation and interactive learning. The case of demand articulation by the Dutch patient organisation VSN indeed matched circumstances of a specific technology (i.e., enzyme replacement therapy for Pompe disease) and a homogeneous user population (Pompe disease patients). However, the case was not restricted to the protected space. Quite exceptionally, the VSN already was proactively involved in the drug R\&D process and clinical trials. But it was also, and less exceptionally, involved in articulation activities related to topics that need to be addressed once technologies enter the wider world, like drug approval, reimbursement and newborn screening. According to the classification scheme, interactions should then increasingly aim at learning how to integrate technology in practice, exploring whether real use conforms expectation, and reducing ambiguities of the technology. The case study shows that some of these functions, notably realising expectations and reducing ambiguities, are already anticipated in demand articulation processes. Demand articulation in an early phase can thus contribute to improved societal embedding of new drugs.

In the case of interactive learning in the DNC, we described the circumstances in terms of a specific technology (i.e., nutrigenomics research for metabolic stress) and heterogeneous users. Especially the latter characterisation requires further discussion. Users were defined as users of knowledge. This turned any participant of the consortium into a user as they participated to learn from each other. We argued that this is a legitimate conceptualisation of the user when talking about interactive learning, especially in the case of emerging technology where predominantly scientific and technological actors interact about scientific knowledge, and both concrete applications and actual (end) users are still absent. The classification scheme thus proves to be relatively independent from how producer, object and user are reciprocally defined. However, this conceptualisation of users is not without repercussions for the position of the case in the classification scheme. If the knowledge developed in the DNC in due course leads to the development of more or less concrete genomics-based technologies or products, the user of this technology might not be 
the same as the user of the underlying knowledge that we studied. As a consequence, the case will shift within the classification scheme for methodological reasons.

What is more, apart from methodological reasons, cases can also move through the scheme as a result of trends and developments within innovation systems or society at large. The possible transition of the health care system towards enhanced genomics-based diagnosis, delineation of individuals as a unique set of predisposition, convergence of food and pharmaceuticals, and personalised therapies and diets might trigger or necessitate a fundamental reform of both the pharmaceutical and the food innovation system. This raises interesting new questions. If these sectors indeed move towards heterogeneous user populations and flexible technology, then the classification scheme suggests that UPI types, such as innofusion and user innovation become increasingly important. But what would these concepts, originating from IT-related innovation studies, actually mean in a health-related context? What are their mechanisms and what conditions do they pre-suppose? What would, for example, be the role of intermediaries in these types of UPI and does proximity still matter as much? Although answers to these questions are beyond the scope of this paper, we think we have at least coined the concepts with which such questions can be addressed.

The second need for realising the potential of the classification scheme to become a useful toolbox for innovation management and policy is to get a grip on the conditions and forms of organisation of UPI. The analysis of the UPI processes, mechanisms, conditions and the outcomes of demand articulation and interactive learning give important points of attention for improving emerging innovation processes, both in the protected space and in the phase of the wider world.

Building on the two exemplary cases, the most important conclusions regarding organising and managing various types of UPI in emerging pharmaceutical and food innovation are:

Firstly, regarding the UPI type, demand articulation, the conditions of demand articulation in a patient organisation include problem-, vision- and agenda-setting, demand synthesis by underlying assumptions, expression and evaluation of demands with other actors, all leading to facilitating emerging pharmaceutical innovation processes. In the context of the role of demand articulation processes in pharmaceutical R\&D processes, the Dutch Neuromuscular Disease Association (VSN) articulated its demand on several issues at several stages of the Pompe drug development process, including compassionate use, expectations of different stakeholders vis$\grave{a}$-vis certain innovations, etc. The results showed that representative intermediary user/patient organisations, such as the VSN, can have a beneficial and steering impact on pharmaceutical innovation processes.

Secondly, with regard to the UPI type, interactive learning, the characteristics for interactive learning in a consortium include stimulation by geographical, cognitive, 
cultural, organisational and regulatory conditions, finally leading to (changing) shared visions and a collective scientific output, leading to "improved" nutrigenomics innovations.

For consortia to interact and learn from each other, we found in the case study of the DNC that a certain amount of cognitive distance and absorptive capacity between the stakeholders turned out to be crucial for innovation in science-based food innovations (e.g., nutrigenomics), as are trust and mutual agreements in case of conflicting interests.

In the pharmaceutical innovation system, intermediary organisations, such as a patient organisation, enter through various first- and second-order converging articulation mechanisms (compassionate use, organising scientific workshops, clinical trials and newborn screening) into ongoing developments - when they try to influence drug research and development pipelines. The intermediary organisation also plays a role in toning down exaggerated expectations of the new technology. However, the presented VSN case should ideally be posed against cases of other intermediary (patient) organisations, because this category of actors is heterogeneously setup. In the food innovation system, an intermediary role is often fulfilled by bridging objects like mouse models.

Zooming in on two types of UPI, namely demand articulation and interactive learning, recommendations could be presented for policy makers and various user groups on how to organise user involvement in emerging innovation processes in the pharmaceutical and food sector in a more effective and efficient way, by focussing on the described mechanisms of demand articulation and interactive learning.

Regarding demand articulation mechanisms, articulation of needs, demands, problems and opportunities/expectations are important by clarifying agenda-setting practices. Bringing in the vision of other actors leads to mobilisation of the creative potential of prospective users. Now the developed Pompe drug is on the verge of stepping into the wider world, the intermediary user organisation plays an important role in learning how to bring the new enzyme replacement therapy technology to all its users, exploring whether the real use conforms expectations and guidelines. What is more, looking for opportunities to broaden the indication area and the spectrum of users (patients with early-onset, juvenile and late-onset Pompe disease) might even turn the case into one of heterogeneous demand, meaning that additional attention should be paid to integrating technology in various practices and to learning by using in these practices.

Regarding mechanisms of interactive learning, it became clear that the nutrigenomics developments are still in the protected space phase, with shifting shared visions about potential nutrigenomics applications and steadily increasing scientific output. Within the studied consortium, broadening of user participation took place via network formation and mechanisms of absorptive capacity (cognitive 
proximity), and exchange of knowledge (presence of knowledge flows). The geographical, organisational and regulatory proximity conditions could facilitate structures for emerging technology development, and codes and networks for frequent interaction between complementary stakeholders. Demands, concerns and opportunities are amongst others articulated by (shifting) shared visions.

Table 1 could be further developed as a toolbox with respect to the management of UPI in emerging pharmaceutical and food innovation systems, helping various stakeholders in organising involvement of users in emerging innovation processes in a more effective and efficient way.

Summarising, this paper shows that systemic differences best account for how UPI should be organised and managed in emerging pharmaceutical and food innovations. One implication for innovation management is that successful forms of UPI, such as demand articulation and interactive learning, cannot be copied from one case to another without taking into account the institutional environment of the innovation system (the development of an emerging technology being co-shaped by a number of geographical, organisational, regulatory and cognitive systemic conditions) and the nature and role of intermediary organisations. Producers of emerging pharmaceutical and food technologies should stay focused on other stakeholders, consumers and patients with specific needs, via intermediary user organisations, consortia or other forms of user-producer linkages. This will help in developing products in a co-evolutionary way towards better societal embedment.

This paper showed that organised UPIs, for example via intermediary user organisations such as the VSN, and via consortia, such as the DNC, are important tools and opportunities for demand articulation and interactive learning involving patient organisations, researchers and private and public organisations.

The results presented in this study should be regarded as tentative due to the exploratory nature of the research carried out. Regarding the classification scheme in Table 1, only two situations were studied, i.e., specific technology in a protected space/wider world with homogeneous users, and specific technology in a protected space with heterogeneous users. As discussed, we endeavour a large program in which we are able to investigate the conditions and processes of UPI in many different circumstances, starting with the food and pharmaceutical innovation system. This paper presented the first results in the context of the integrative classification frame. Yet, further research should be conducted along various lines of research. Firstly, similar case studies should focus on other types of UPI and/or in different kinds of cases in order to more fully realise the practical relevance of the classification scheme. Secondly, the same research can be conducted in other high-income countries. Then, the results could be combined with those from the Netherlands to carry out a more reliable international comparative study and to emphasise the role of institutional and cultural differences in the organisation of UPI. Thirdly, when 
in future the first nutrigenomics innovations are actually introduced to the market (stepping in the wider world), nutrigenomics development trajectories can be compared with pharmaceutical trajectories on a case-study basis, and the mechanisms of UPIs could be studied more in depth. Fourthly, further research should be done to assess the viability of a trend towards personalised therapies and diets. The results of current studies could be used as a baseline for such assessment. Finally, future research should also provide insight into the extent to which the results of this study are useful in other sectors with emerging technologies, such as IT, nanotechnology and pharmacogenomics, thereby increasing the understanding of the role of UPIs in innovation processes, also comparing emerging innovation systems, such as genomics, with more stabilised ones, such as IT.

\section{References}

Akrich, M (1995). User representations: practices, methods and sociology. In Managing Technology in Society. The Approach of Constructive Technology Assessment, A Rip, J Misa and J Schot (eds.), pp. 167-184. London and New York: Pinter Publishers.

Atun, RA, I Gurol-Urganci and D Sheridan (2007). Uptake and diffusion of pharmaceutical innovations in health systems. International Journal of Innovation Management, 11(2), 299-321.

Atun, RA and D Sheridan (2007). Editorial: innovation in health care: the engine of technological advances. International Journal of Innovation Management, 11(2), 5-10.

Autio, E, S Kanninen and R Gustafsson (2008). First- and second-order additionality and learning outcomes in collaborative R\&D programs. Research Policy, 37(1), 59-76.

Bijker, WE (1995). Of Bicycles, Bakelites, and Bulbs. Toward a Theory of Sociotechnical Change. Cambridge, MA: The MIT Press.

Boon, WPC, EHM Moors, S Kuhlmann and REHM Smits (2008). Demand articulation in intermediary organisations: the case of orphan drugs in the Netherlands. Technological Forecasting and Social Change, 75(5), 644-671.

Boon, WPC (2007a). Storyline of Herceptin Reimbursement - Case Study Report on the Dutch Breast Cancer Association. Utrecht: Utrecht University.

Boon, WPC (2007b). Case Study Report on the Dutch Neuromuscular Disease Association. Utrecht: Utrecht University.

Boon, WPC (2008, In Press). Demanding Dynamics - Demand Articulation of Intermediary Organisations in Emerging Pharmaceutical Innovations (dissertation). Utrecht: Utrecht University.

Boschma, RA and JG Lambooy (1999). Evolutionary economics and economic geography. Journal of Evolutionary Economics, 9(4), 411-429.

Boschma, R (2005). Proximity and innovation: a critical assessment. Regional Studies Abingdon 00039/00001 (2005-01-01), 61-75. 
Bucchi, M and F Neresini (2008). Science and public participation. In The Handbook of Science and Technology Studies, EJ Hackett, O Amsterdamska, M Lynch and J Wajcman (eds.), pp. 449-472. Cambridge, Massachusetts: The MIT Press.

Clark, KB (1985). The interaction of design hierarchies and market concepts in technological evolution. Research Policy, 14, 235-251.

Cohen, WM and DA Levinthal (1990). Absorptive capacity: a new perspective on learning and innovation. Administrative Science Quarterly, 35(1), 128-152.

Collingridge, D (1980). The Social Control of Technology. London: Pinter.

COM (2007). Together for health: a strategic approach for the EU 2008-2013. Proc. of the

White Paper, Presented by the Commission of the European Communities, Brussels, http://ec.europa.eu/health/ph_overview/strategy/health_strategy_en.htm [23 October 2007].

Coombs, R et al. (2001). Technology and the Market. Demand, Users and Innovation. Northampton, MA: Edward Elgar.

Cooper, RG (1993). Winning at New Products: Accelerating the Process from Idea to Launch, 2nd Ed., Cambridge, MA: Addison-Wesley.

Dasgupta, P and PA David (1994). Toward a new economics of science. Research Policy, 23, 487-521.

DNC (Dutch Nutrigenomics Consortium), internal document for website www. nutrigenomicsconsortium.nl.

Doloreux, D (2004). Regional networks of small and medium sized enterprises: evidence from the metropolitan area of Ottawa in Canada. European Planning Studies, 12(2), 173-189.

Dosi, G et al. (2006). How much should society fuel the greed of innovators?: on the relations between appropriability, opportunities and rates of innovation. Research Policy, 35(8), 1110-1121.

FDA (2005). Innovation or stagnation. Challenge and opportunity on the critical path to new medical products. FDA report.

Fischoff, B (1995). Risk perception and communication unplugged: twenty years of progress. Risk Analysis, 15(2), 137-145.

Fleck, J (1994). Learning by trying. The implementation of configurational technology. Research Policy, 23(6), 637-652.

Fleck, J (1988). Innofusion or diffusation? The nature of technological developments in robotics. Edinburgh PICT Working Paper.

Franke, N and E Von Hippel (2003). Satisfying heterogeneous user needs via innovation toolkits: the case of Apache security software. Research Policy, 32(7), 1199-215.

Feldman, MP (1994). The Geography of Innovation. Dordrecht: Kluwer.

Frenken, K and FG Van Oort (2004). The geography of research collaboration: theoretical considerations and stylised facts in biotechnology in Europe and the United States. In Regional Economies as Knowledge Laboratories, P Cooke and A Piccaluga (eds.), pp. 38-57. Cheltenham, UK and Northampton, MA: Edward Elgar.

Garrety, K and R Badham (2004). User-centered design and the normative politics of technology. Science, Technology \& Human Values, 29(2), 191-212. 
Geels, FW (2002). Understanding the Dynamics of Technological Transitions. A coevolutionary and socio-technical analysis. PhD thesis, Twente University Press.

Gertler, MS (2003). Tacit knowledge and the economic geography of context, or the undefinable tacitness of being (there). Journal of Economic Geography, 3, 75-99.

Geurts, J (1993). Omkijken naar de toekomst, lange termijn verkenningen in beleidsexercities (Looking Back to the Future, Longterm Foresight Studies in Policy Exercises). Tilburg: Samson H.D. Tjeenk Willink.

Griffin, A and JR Hauser (1993). The voice of the customer. Marketing Science, 12(1), 1-27.

Griffin, A (1996). Obtaining customer needs for product development. In The PDMA Handbook of New Product Development, MD Rosenau, Jr. (ed.), pp. 153-166. New York: John Wiley \& Sons Inc.

Hamel, G and CK Prahalad (1994). Competing for the Future. Boston, MA: Harvard Business School Press.

Hoogma, R and JW Schot (2001). How innovative are users? A critique of learning-bydoing and -using. In Technology and the Market. Demands, Users and Innovation, R Coombs, K Green, A Richards and V Walsh (eds.), pp. 216-233. Cheltanhem, UK, Edward Elgar.

Howells, JRL (2002). Tacit knowledge, innovation and economic geography. Urban Studies, 39(5), 871-884.

Kaput, J, JM Ordovas, L Ferguson, B van Ommen, RL Rodriguez and L Allen (2005). Horizons in nutritional science. The case for strategic alliances to harness nutritional genomics for public and personal health. British Journal of Nutrition, 94, 623-632.

Kaput, J, A Perlina, B Hatipoglu, A Bartholomew and Y Nikolsky (2007). Nutrigenomics: concepts and applications to pharmacogenomics and clinical medicine. Pharmacogenomics, 8(4), 369-390.

Lettl, C, C Herstatt and HG Gemuenden (2006). Users' contribution to radical innovation: evidence from four cases in the field of medical equipment technology. $R \& D$ Management, 36(3), 251-272.

Lundvall, BA (1988). Innovation as an interactive process: From user-producer interaction to the national system of innovation. In Technical Change and Economic Theory, Dosi, G, C Freeman, R Nelson, G Silverberg and L Soete (eds.), pp. 349-369. London: Pinter Publishers.

Lundvall, BA (1992). National Systems of Innovation: Towards a Theory of Innovation and Interactive Learning. London: Pinter Publishers.

Lütje, C (2003). Customers as co-inventors: an empirical analysis of the antecedents of customer-driven innovations in the field of medical equipment. Proc. of the 32nd Annual Conference of the European Marketing Academy (EMAC), Glasgow.

Malmberg A and P Maskell (1999). Guest editorial: localized learning and regional economic development. European Urban and Regional Studies, 6(1), 5-8.

Martin, P (2001). Great expectations: the construction of markets, products and user needs during the early development of gene therapy in the USA. In Technology and the 
Market. Demand, Users and Innovation, R Coombs, K Green, A Richards and V Walsh (eds.), pp. 38-67. Northampton, MA: Edward Elgar.

Menrad, K (2003). Market and marketing of functional food in Europe. Journal of Food Engineering, 56, 181-188.

Moors, EHM, C Enzing, A Van der Giessen and REHM Smits (2003). User-producer interactions in functional genomics innovations. Innovation: Management, Policy \& Practice, 5(2-3), 120-143.

Moors, EHM and H Schellekens (2008). Medical biotechnology and sustainable drug development. In General Aspects in Biopharmaceuticals for European Hospital Pharmacists, H Schellekens and AG Vulto (eds.), Chap. 1, Mol(B): Pharma Publishing \& Media Europe 2008, 7.

Nahuis, R and H Van Lente (2008). Where are the politics? Perspectives on democracy and technology. Science, Technology \& Human Values 33(5).

Nahuis, R, EHM Moors and REHM Smits (2008). User producer interaction in context. A typology. Working Paper. Innovation Studies Group, Utrecht: Utrecht University.

Nelson, RR and SG Winter (1982). An Evolutionary Theory of Economic Change. Cambridge/London: The Belknap Press of Harvard University Press.

Oudshoorn, N and T Pinch (2003). How Users Matter. The Co-construction of Users and Technology. Cambridge, MA: MIT Press.

Poole, MS, AH Van de Ven, K Dooley and ME Holmes (2000). Organizational Change and Innovation Processes. Oxford: Oxford University Press.

Renn, O (1998). Three decades of risk research: accomplishments and new challenges. Journal of Risk Research, 1(1), 49-72.

Rip, A and R Kemp (1998). Technological change. In Human Choice and Climate Change, S Rayner and EL Malone (eds.), Vol. 2, Chap. 6, pp. 327-399. Ohio: Battelle Press.

Rip, A and JW Schot (2002). Identifying loci for influencing the dynamics of technological development. In Shaping Technology, Guiding Policy. KH Sørensen and R Williams, (eds.), pp. 155-172. Cheltenham, UK: Edward Elgar.

Rohracher, H (2005). User Involvement in Innovation Processes. Strategies and Limitations from a Socio-Technical Perspective. Munchen: Profil Verlag.

Rosenberg, N (1982). Inside the Black Box. Technology and Economics. Cambridge, MA: Cambridge University Press.

Royal Society (2005). Personalised Medicine: Hopes and Realities. London: The Royal Society.

Sabatier, PA (1987). Knowledge, policy-oriented learning and policy change: an advocacy coalitions framework. Knowledge, 8, 17-50.

Schmidt, JB and RJ Calantone (2002). Escalation of commitment during new product development. Journal of the Academy of Marketing Science, 30, 103-118.

Silverstone, R and E Hirsch (1992). Consuming Technologies. Media and Information in Domestic Spaces. London and New York: Routledge.

Smits, REHM (2002). Innovation studies in the 21th century: questions from a user's perspective. Technological Forecasting and Social Change, 69, 861-883. 
Smits, R and P Den Hertog (2007). Technology assessment and the management of technology in economy and society. International Journal of Foresight and Innovation Policy, 3(1), 28-52.

Smits, REHM and WPC Boon (2008). The role of users in innovation in the pharmaceutical industry. Drug Discovery Today, 13(7/8), 353-359.

Star, SL and JR Griesemer (1989). Institutional ecology, 'translations' and boundary objects: amateurs and professionals in Berkeley's Museum of vertebrate zoology, 1907-39. Social Studies of Science, 19, 387-420.

Stewart, J and R Williams (2005). The wrong trousers? Beyond the design fallacy: social learning and the user. In Handbook of Critical Information Systems Research: Theory and Application, D Howcroft and E Trauth (eds.), pp. 195-221. Cheltenham: Edward Elgar.

Stirling, A (1998). Risk at a turning point? Journal of Risk Research, 1(2), 97-110.

Teubal, M (1979). On user needs and need determination: aspects of the theory of technological innovation. In Industrial Innovation. Technology, Policy and Diffusion, MJ Maker (ed.), pp. 266-289. London: Macmillan Press.

Triggle, D (2007). Treating desires not diseases: a pill for every ill and an ill for every pill? Drug Discovery Today, 12(3/4), 161-166.

Trusheim, MR, ER Berndt and FL Douglas (2007). Stratified medicine: strategic and economic implications of combining drugs and clinical biomarkers. Nature Reviews Drug Discovery, 6, 287-293.

Urala, N and L Lähteenmäki (2007). Consumers' changing attitudes towards functional food. Food Quality and Preference, 18, 1-12.

Utterback, JM (1994). Mastering the Dynamics of Innovation. Boston, Massachussets: Harvard Business School Press.

Vandeberg, RLJ and EHM Moors (2007). A framework for interactive learning in emerging technologies. Working Paper. Innovation Studies Group. Utrecht: Utrecht University.

Vandeberg, RLJ and WPC Boon (2008). Anticipating emerging technologies. Genomics, Society, Policy Journal. (Forthcoming).

Vandeberg, RLJ (2008a). Interactive Learning in Emerging Technologies: the Case of the Dutch Nutrigenomics Consortium 2007. Utrecht: Utrecht University — Department of Innovation Studies.

Vandeberg, RLJ (2008b). Interactive Learning in Emerging Technologies: the Case of the German Competence Network Metabolic Syndrome. 2007. Utrecht: Utrecht University - Department of Innovation Studies.

Vandeberg, RLJ (forthcoming). A framework for interactive learning in emerging technologies - Comparative case studies in national nutrigenomics consortia. Utrecht: Utrecht University (dissertation).

Van der Valk, T (2007). Technology Dynamics, Network Dynamics and Partnering - The Case Of Dutch Dedicated Life Sciences Firms. Utrecht: Utrecht University.

Van Kleef, E, HCM Van Trijp and P Luning (2005). Consumer research in the early stages of new product development: a critical review of methods and techniques. Food Quality and Preference, 16(3), 181-201. 
Van Lente, H, MP Hekkert, REHM Smits and B Van Waveren (2003). Roles of systemic intermediaries in transition processes. International Journal of Innovation Management, 7(3), 1-33.

Verbeke, W (2005). Consumer acceptance of functional foods: sociodemographic, cognitive and attitudinal determinants. Food Quality and Preference, 16, 45-57.

Von Hippel, E (1988). The Sources of Innovation. New York: Oxford University Press.

Weterings, ABR (2006). Do Firms Benefit From Spatial Proximity? Utrecht: Utrecht University. 